\title{
The ovo gene required for cuticle formation and oogenesis in flies is involved in hair formation and spermatogenesis in mice
}

\author{
Xing Dai, ${ }^{2}$ Christopher Schonbaum, ${ }^{2}$ Linda Degenstein, ${ }^{1,2}$ Wenyu Bai, ${ }^{2}$ Anthony Mahowald, ${ }^{2,3}$ \\ and Elaine Fuchs $\mathbf{s}^{1,2,3}$
}

${ }^{1}$ Howard Hughes Medical Institute, ${ }^{2}$ Department of Molecular Genetics and Cell Biology, ${ }^{3}$ Committee on Developmental Biology, The University of Chicago, Chicago, Illinois 60637 USA

The D rosophila svb/ovo gene gives rise to differentially expressed transcripts encoding a zinc finger protein. svb/ovo has two distinct genetic functions: shavenbaby (svb) is required for proper formation of extracellular projections that are produced by certain epidermal cells in late-stage differentiation; ovo is required for survival and differentiation of female germ cells. We cloned a mouse gene, movol encoding a nuclear transcription factor that is highly similar to its fly counterpart in its zinc-finger sequences. In mice, the gene is expressed in skin, where it localizes to the differentiating cells of epidermis and hair follicles, and in testes, where it is present in spermatocytes and spermatids. Using gene targeting, we show that movol is required for proper development of both hair and sperm. movol ${ }^{-1-}$ mice are small, produce aberrant hairs, and display hypogenitalism, with a reduced ability to reproduce These mice also develop abnormalities in kidney, where movol is also expressed. Our findings reveal remarkable parallels between mice and flies in epidermal appendage formation and in germ-cell maturation. Furthermore, they uncover a phenotype similar to that of Bardet-Biedl syndrome, a human disorder that maps to the same locus as human ovol.

[Key Words: ovo; skin; hai r; spermatogenesis; knockout mice]

Received August 3, 1998; revised version accepted September 9, 1998.

Conservation of molecular mechanisms throughout evoIution, in particular, between flies and mammals, is not unprecedented. In recent years, numerous cases have been reported in which mammalian homologs of developmentally important Drosophila genes perform similar functions and participate in similar pathways as their fly relatives. As the organ separating the animal body from its environment, skin/skin appendages in both flies and mice carry out essential protective and sensory functions. Comparative studies suggest that genes involved in patterning the Drosophila larval epi dermis, including those in the decapentaplegic, wingless, and Sonic hedgehog pathways, are also utilized in patterning the mammalian skin (for review, see Fuchs 1995; Willert and N usse 1998). However, little is known about the molecular and functional conservation of the many Drosophila genes implicated in epi dermal development, cuticle formation, and cuticle-denticle differentiation (for review, see Martinez Arias 1993). Less conservation among these processes has been anticipated, given the fact that in fly, a single-layered epidermis produces and

${ }^{3}$ Corresponding author.

E-MAIL lain@midway.uchicago.edu; FAX (773) 702-0141. secretes cuticle and forms denticles. In contrast, the surface ectoderm of mammals is the progenitor of epi dermis and hair follicles, each composed of multiple, differentiating cell layers.

Germ-line sex determination is another process strikingly different between flies and mice. In Drosophila, male is the default state of germ-line development (Granadino et al. 1993), and the female pathway requires both an inductive signal from soma and an autonomous signal dependent upon the $X$ chromosome to autosome ratio (for review, see Wei and M ahowal d 1994; Cline and Meyer 1996; Lin 1997). In mammals, germ-line sex determination depends on nonautonomous and autonomous factors, but in a very different way from Drosophila (for review, see Bogan and Page 1994; McLaren 1995; Capel 1998).

The ovo locus in Drosophila is interesting in that it encodes proteins involved in both of these evolutionarily diverse processes. The ovo locus produces multiple transcripts that originate from at least two promoters and share largel y overlapping coding sequences (Garfinkel et al. 1994; Mevel-Ninio et al. 1995). Defects affecting either upstream regulatory elements or the coding portion of the ovo locus result in the shavenbaby (svb) pheno- 
type (Wieschaus et al . 1984). Although isol ated originally in a search for mutants in larval cuticle patterning, svb mutations affect the number and size of denticle setal belts but not the pattern of denticles within a segment. Consistent with this phenotype, svb transcripts are detected in those epidermal cells that produce and secrete cuticle that gives rise to these extracellular appendages Iate in larval devel opment (Garfinkel et al. 1994; M evel$\mathrm{N}$ inio et al. 1995). svb mutants rarely survive, but the few adult males that do survive display mildly curved bristles (Busson et al. 1983; Oliver et al . 1987), suggesting a role for svb in late-stage differentiation of epidermal appendages in larvae and in adult flies.

Recessive-null alleles of the ovo locus or mutations affecting downstream regulatory elements result in female-specific sterility caused by loss of embryonic germ cells (Oliver et al. 1987). Less severe mutations produce viable germ-line cells that exhibit defective oogenesis (Oliver et al. 1987) or ovarian tumors with male germline characteristics (Oliver et al. 1990). Dominant ovo mutants antagonize wild-type Ovo function and result in abnormal oogenesis (Busson et al. 1983; M evel-N inio et al. 1996; Andrews et al. 1998). Consistent with its complex phenotype in the female germ line, ovo expression was reported in the germarium, in nurse cells early during oogenesis, and in the germ-line precursor pole cells (Mevel-N inio et al. 1991; Garfinkel et al. 1994). ovo is also expressed in embryonic male germ cells and in germ-line stem cells of adult testis, but no defects in male germ cell production and/or spermatogenesis have been observed (M evel-N inio et al. 1995). Thus, ovo has been impli cated in oogenesis and in femal e germ-line sex determination, where it is considered a candidate for the target gene of somatic feminization signal (Oliver et al. 1994).

How Ovo and Svb function to regulate such diverse processes remains unexplored. However, several lines of evidence suggest that the protein(s) might act as transcription factors. The carboxy-terminal segment of Ovo/ Svb contains four zinc fingers of the $\mathrm{C}_{2} \mathrm{H}_{2}$ Class, a group of proteins known to bind DNA with strong affinity (Mevel-Ninio et al. 1991, 1995; Garfinkel et al. 1992, 1994). In addition, bacterially expressed Ovo/Svb protein has been shown to bind to multiple sites at or near the ovo and ovarian tumor promoters (Lu et al. 1998). These results are consistent with genetic data that the ovo gene is controlled by an autoregulatory mechanism (Garfinkel et al. 1994; Mevel-Ninio et al. 1996), and that ovo and ovarian tumor function in a common pathway (Pauli et al. 1993). Unequivocal evidence that Ovo/Svb function as transcription factors and the identification of additional candidate genes that might be transcriptionally controlled by Ovo/Svb await further investigation.

Because ovo/svb is an example of a single locus with the capacity to carry out two independent functions that are both seemingly diverse across evolution, it is an attractive starting point to rigorously test for similarities between fly and mouse epidermal and/or reproductive differentiation. Here we report the characterization of a mouse ovo/svb-related gene and its expression and func- tion. We show that the mouse protein, mOvol, is not only expressed in similar tissues as its Drosophila homolog, but it also plays essential roles in the development of these tissues, in an analogous manner to the fly. Wealso provide evidence for a possible mechanism of its function, that is, as a transcriptional regulator.

\section{Results}

Cloning of a mouse ovol cDNA and the detection of movol mRNAs in mouse skin but not in ovary

Using a degenerative PCR strategy, followed by screening of a mouse skin cDNA library, we identified a mouse ovo cDNA. The compl ete sequence and characterization of this CDN A will be reported elsewhere (C. Schonbaum and $A$. Mahowald, in prep.). Encompassing roughly half of the encoded 30-kD protein, the zinc-finger domains of mouse Ovo share $73 \%$ identity with equivalent segments of Drosophila Ovo/Svb (Garfinkel et al. 1994) and 94\% identity with human Ovol (hOvol; Chidambaram et al . 1997). On the basis of this similarity, we will refer to our sequence as mouse Ovola (mOvola). As this work was in progress, the sequence of another mouse ovo cDNA encoding a similar 31-kD protein was reported (M asu et al. 1998). The reported sequence shares $77 \%$ identity with mOvol within the zinc-finger domains, and $49 \%$ overall; its zinc-finger domains share $98 \%$ identity with a second human Ovo protein, hOvo2, reported as an expressed sequence tag (EST) in the database (Hillier et al. 1995). We therefore refer to this sequence as mOvo2. The zinc-finger region of mOvola is more simiIar to Drosophila Ovo than mOvo2; however, both mouse Ovo proteins diverge from Drosophila Ovo outside these domains. Curiously, Drosophila Ovo has a large ami no-terminal segment not present in these mammalian Ovo proteins.

To further explore possible parallels between Drosophila and mouse ovo, we conducted Northern blot analysis on poly $(A)^{+}$RN As isol ated from mouse skin and ovary tissues. Under stringent conditions, three transcripts of $3.5,2.5$, and $2.0 \mathrm{~kb}$ were detected in adult mouse skin (Fig. 1A). The strongest hybridizing band was $2.0 \mathrm{~kb}$, consistent with the size of our cDN A. The presence of multiple movol transcripts was interesting in light of prior studies on the Drosophila ovo/svb gene, where at least three different transcripts have been partially or fully characterized (M evel-N inio et al. 1995; Andrews et al. 1998). A complete analysis of the larger transcripts is beyond the scope of the present study.

We were surprised that we did not detect hybridization with the movol probe in the RNA preparation from adult ovary. The absence of hybridization could not be attributed to the quality of ovary RN A, since the glyceraldehyde-3-phosphate dehydrogenase (GAPDH) RNA control probe hybridized to a single, appropriately sized band. RT-PCR analysis revealed low levels of movol transcri pts in ovary and isolated mouse eggs (not shown). Whether movol is more abundantly expressed in some transient developmental stage(s) or perhaps in a small 
Figure 1. Examining movol in skin and ovary. (A) Northern analysis of skin and ovary RN As, loaded at $2 \mu \mathrm{g}$ of polyA ${ }^{+} \mathrm{RN} A$ per lane. Transcripts hybridizing with the movol and GAPDH (control) probes are shown. (B-E) In situ hybridizations of digoxygenin-labeled movol cRNA on embryonic skin from E13.5 to E16.5. In C, the devel oping epidermis at the embryo's arm-body junction is shown. (F) In situ hybridizations of movol probe on newborn back skin. (E) Ectoderm; (S) suprabasal layers; (B) basal layer. Broken lines denote basement membrane. Arrows denote hybridizing signals in precortical cells of hair follicles. Bar, $50 \mu \mathrm{m}$ in B-E; $80 \mu \mathrm{m}$ in F.

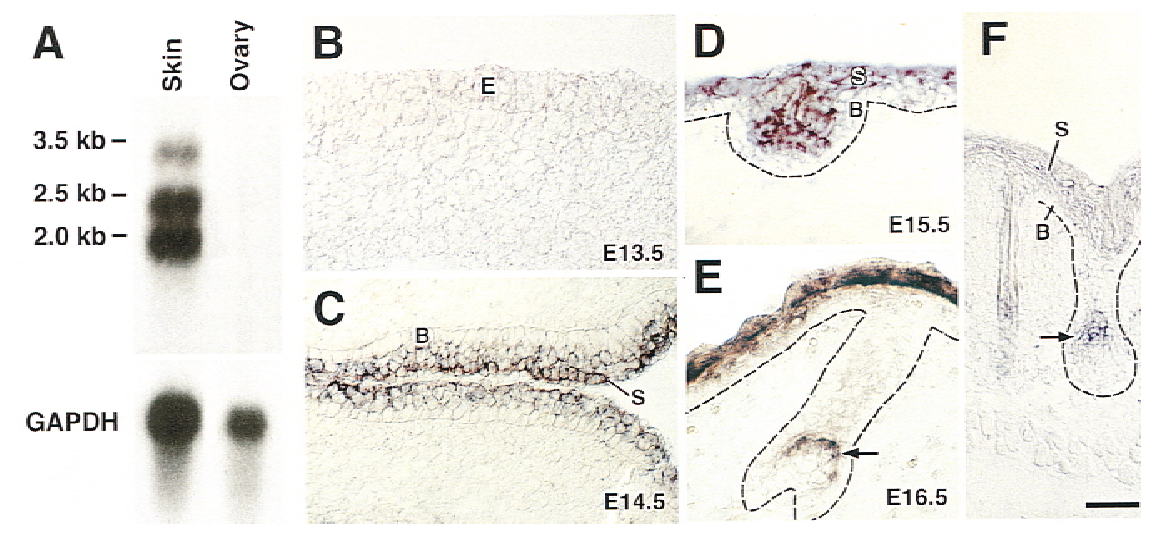

ing cultures contained few transcripts that hybridized with a movol-specific cDN A (Fig. 2). Within $24 \mathrm{hr}$ after increasing cal cium to $1.2 \mathrm{~mm}$, a marked up-regulation of movol RN As was observed. Intriguingly, the appearance of movol mRNAs preceded those of $\mathrm{K} 1$ encoding an early marker of terminal differentiation (Fuchs 1995).

The 30-kD mOvola protein concentrates in the nucleus of epithelial cells

Sequence similarities to known transcription factors and the nuclear localization of recombinant Drosophila Ovo fusion proteins have led to the hypothesis that Drosophila Ovo is a DNA-binding protein with transcripti onal regulatory activity (M evel-N inio et al. 1991, 1995; Garfinkel et al. 1992; Lu et al. 1998). To test this possibility for mOvola, we engineered a vector to drive movola expression under the control of the cytomegalovirus (CMV) promoter. To detect the recombinant protein, we generated a polyclonal anti-mOvol antibody. When Cos monkey epithelial cells were transfected with the CMV-mOvola expression vector, a protein of $30 \mathrm{kD}$ was produced, which by immunoblot analysis was detected by anti-mOvol (Fig. 3 A,B). This 30-kD protein was not produced by mock-transfected Cos cells, confirming its identity as movola.

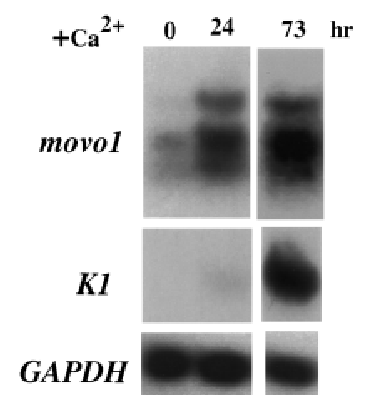

Figure 2. Northern analysis of RN As isolated from mouse keratinocytes cultured in the presence of $1.2 \mathrm{mM} \mathrm{Ca}^{2+}$ for the hours (hr) indicated. Twenty micrograms of total RNAs was loaded in each lane. The same blot was stripped and rehybridized with the probes indicated. 


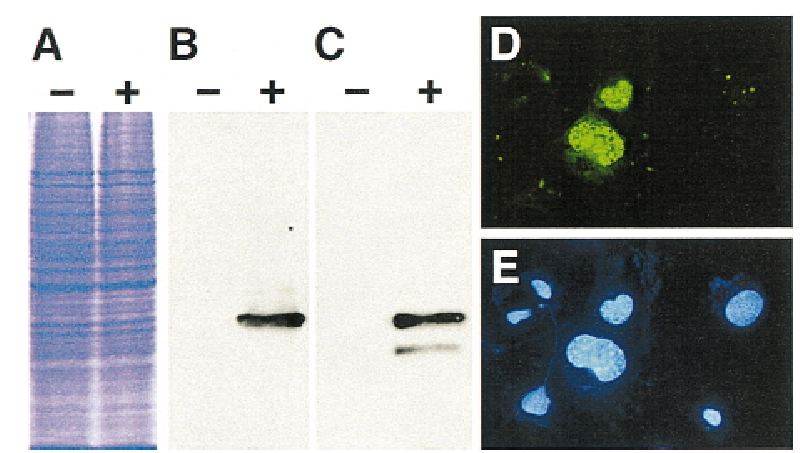

Figure 3. Nuclear localization of mOvola in transfected Cos cells. (A) Coomassie blue staining of SDS-PAGE-resolved proteins from Cos cells transfected with empty vector $(\rightarrow$ or with CMV-movola (+). (B) Anti-mOvol immunoblot analysis of same extracts in A. Chemiluminescence was used to visualize the signal. Major band is at $30 \mathrm{kD}$. (C) Anti-mOvol immunobl ot analysis of nuclear extracts prepared from Cos cells transfected as in A. N ote: The minor $\sim 25-\mathrm{kD}$ band is a degradation product of the full-length protein as its presence in repeated experiments was variable. (D,E) Anti-mOvol (green) and DAPI (blue) immunofluorescence of Cos cells transfected with CMV-movola. Note: Anti-mOvol labeling restricted to the nuclei of transfected cells. Bar, $50 \mu \mathrm{m}$ in D and $\mathrm{E}$.

To determine mOvola's location, we repeated the transfection and immunoblot experiments, this time making nuclear extracts of CMV-mOvola and mocktransfected cells. As shown in Figure 3C, mOvola was detected in this nuclear fraction. Immunofluorescence Iocalization confirmed that anti-movol recognized a nuclear protein restricted to the transfected cells (Fig. 3, $D, E)$. In agreement with this result, we noted the presence of a putative nuclear localization signal (KKIHGVQQKYAYKERRA) at amino acid position 193 of the protein.

A nalysis of the function(s) of nuclear mouse Ovol proteins must await a comprehensive anal ysis of the various mOvol isoforms and an exploration into their ability to regulate specific genes or processes involved in terminal differentiation. However, the existence of Drosophila svb/ovo and mouse ovol transcripts in differentiating epidermis is intriguing and raises the possibility that conservation of transcriptional regulatory sequences may exist within the ovo/svb class of genes of different species.

Expression of movol mRNAs in testis and kidney but not in many other tissues

A more extensive analysis of tissues revealed movol mRNAs in testis and kidney, and weakly in lung but absent in many other tissues (Fig. 4). As before, three hybridizing bands were detected, although their relative levels were somewhat different from those observed in skin. Interestingly, the tissue distribution of movol mRNAs appeared to be distinct from that reported for movo2, which appeared to be restricted to testis, al- though skin was not examined (M asu et al. 1998). Whether there is an as yet unidentified mouse ovo gene that will be expressed in female germ-line development awaits future studies.

\section{Generation of movol $^{-1-}$ mice}

Given the complexities of transcriptional regulation of the ovo genes in flies and mice, and the partially distinct expression patterns of the two known mouse ovo genes, we turned to a knockout strategy to examine the functional importance of mOvol. Upon screening a 129/Sv mouse genomic library, two positive movola-hybridizing clones were identified. A partial restriction map of the movol genomic DNA is shown in Figure 5A. The positioning of the exon-intron structure was determined by partial sequencing and is shown at the top of the figure. Southern blot analysis using several different probes detected only a single band, indicative of a single movol gene (Fig. 5B-D; data not shown).

Because all of the ovo locus transcripts seem to encode the zinc finger domains, we designed a targeting vector to del ete these sequences, contained entirely within exons 3 and 4 of the movol gene (Fig. 5A). The 5.5- and 1.5-kb flanking movol genomic fragments were used as $5^{\prime}$ and $3^{\prime}$ arms, respectively. The phosphoglycerate kinase 1 (PGK) promoter-driven neomycin-resistance gene was used for positive selection with G418, and the PGK promoter-driven herpes thymidine kinase (tk) gene was used for negative sel ection with Gancyclovir.

Of $130 \mathrm{R} 1$ strain ES clones that survived in the presence of G418 and Gancyclovir, 11 scored positive for the homol ogous recombination event, as judged by Southern blot analysis (Fig. 5B,C). These clones were also examined using a radiolabel ed probe corresponding to the neo gene to verify that no random integration of the vector had occurred el sewhere in the ES genome (not shown).

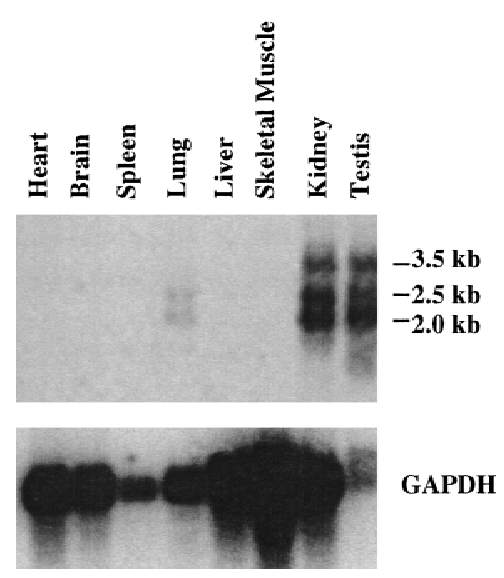

Figure 4. Tissue-specific expression of movol RNAs. Poly $(A)^{+}-$RN As were hybridized with a movol-specific probe (top). The blot was then stripped and rehybridized with a GAPDH probe (bottom). The sizes of the three movol transcripts are indicated at the right. 
A

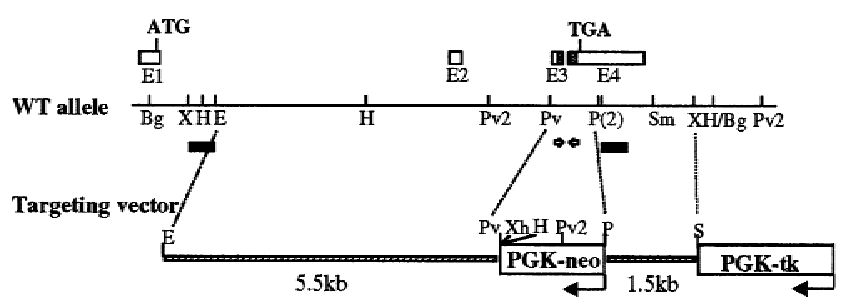

Mutant allele

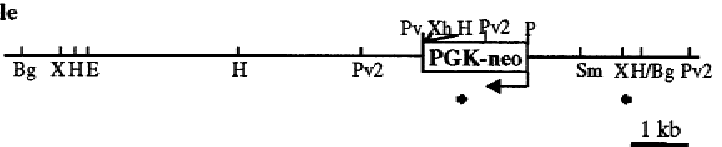

B

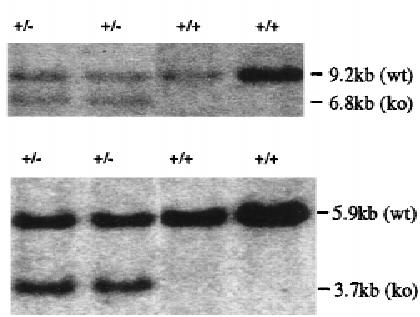

D

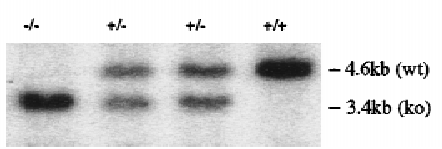

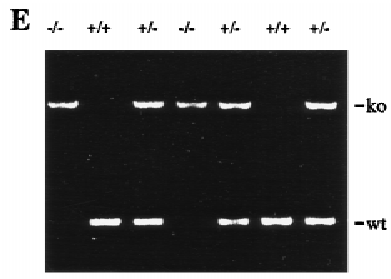

F skin

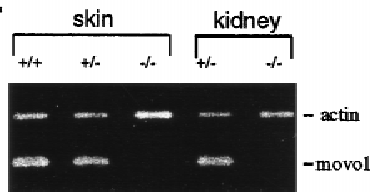

Figure 5. Disruption of movol gene in ES cells and in mice. (A) Stick diagrams of the movol locus (top), targeting vector (middle), and mutant locus resulting from homologous recombination (bottom). Exons (E1-E4) are shown as boxes above the wild-type allele. Translation initiation codon (ATG) and stop codon (TGA) are as indicated; shaded segments denote zinc finger domains. Black bars denote $5^{\prime}$ and $3^{\prime}$ probes used for Southern blot analysis; hatched boxes denote movol sequences used for arms. (Bg) Bglll; (X) Xbal; $(H)$ HindlII; (E) EcoRI; (Pv2) Pvull; (Pv) Pvul; (P) Pstl; (S) Sall; (Sm) Smal; (Xh) Xhol. (B-D) Southern blot analyses of genomic D N As from representative $\mathrm{ES}$ clones (B, 5' probe; $C$, 3' probe) and mouse tails ( $D, 3^{\prime}$ probe). DN As were digested with Xbal-Xhol (B), Hindlll (C), or Pvull (D). (E) PCR analysis of genomic DN As from mouse tails. The pair of primers denoted by black arrows in A generated a 2.5-kb product diagnostic for homologous recombination (ko band). The pair of primers denoted by white arrows in A generated a 330-bp product unique for the wild-type allele (wt band). (F) RT-PCR analysis of total RN As isolated from skin and kidney of movol ${ }^{+++}$, movol ${ }^{+1-}$, and $\mathrm{movol}^{-1-}$ mice. Set of primers used generated a band corresponding to the targeted zinc finger domains of movol. Actin primers were used as an internal control.

Two of these clones were used to generate movol ${ }^{-1-}$ mice. Both contributed to the germ line, as verified by Southern bl ot and PCR analysis of mouse tail DN As (Fig. $5 \mathrm{D}, \mathrm{E})$.

To examine the outcome of movol RN A synthesis in the mutant mice, we used primers specific for sequences within the zinc finger region for RT-PCR analysis. A fragment of the expected size was generated in skin and kidney RNAs from wild-type $(H+)$ and heterozygous $(t-)$ mice, but not from homozygous movo1 $1^{-1-}$ mice (Fig. 5F). By $\mathrm{N}$ orthern blot analysis, some large transcripts were generated from the mutated locus, as is often typical in gene targeting events. However, the two most abundantly expressed transcripts in wild-type skin were absent from homozygous movo1 ${ }^{-1-}$ skin RNAs (not shown). Thus, it is likely that the movol locus was functionally inactivated as a consequence of the targeting event.

movo $1^{-1-}$ skin morphology is largely normal, but mice have a ruffled hair coat and hair abnormalities

At the light microscopy level, no obvious morphological differences were observed in epidermis or its appendages (Fig. 6). Additionally, expression and activity of suprabasal markers of terminal differentiation appeared normal (for review, see Fuchs 1995). Our analysis included (1) involucrin and K1 expressed early in epi dermal differentiation; (2) filaggrin and lori crin expressed at later stages of epidermal differentiation; (3) transglutaminase activated late in epidermal and hair follicle differentiation upon an influx in intracellular calcium pools; and (4) hair-specific keratins and cuticle/inner root sheath-specific trichohyalin (for representative examples, see Fig.

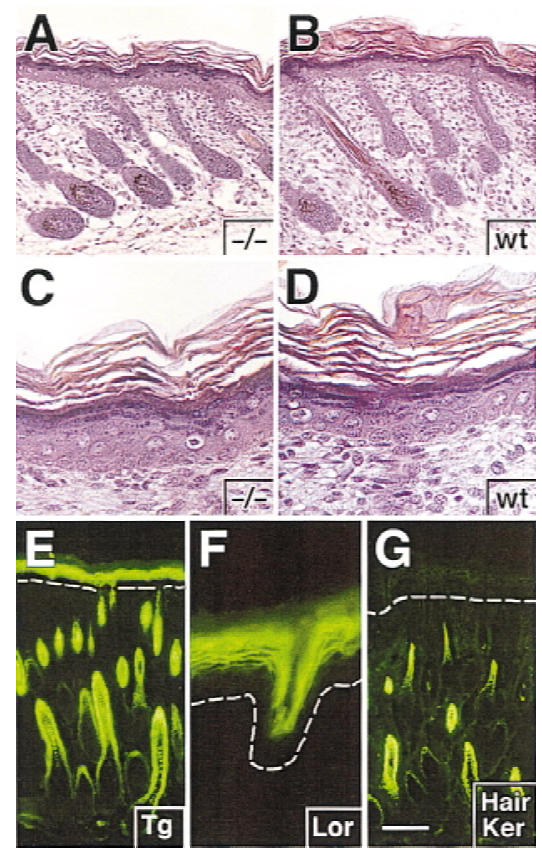

Figure 6. Morphology and biochemistry of $\mathrm{movol}^{-1-}$ back skin. Back skins of a newborn movol ${ }^{-1-}$ mouse and control littermate (wt) were processed for histology and immuofluorescence microscopy. (A-D) Hematoxylin- and eosin-stained sections. (E) Immunofluorescence assay for transglutaminase ( $\mathrm{Tg}$ ) activity in movol ${ }^{-1-}$ back skin. (F,G) Immunofluorescence staining of movol $^{-1-}$ back skin with antibodies to loricrin (Lor, F) and hair keratins (hair ker, G). Immuofluorescence patterns were indistinguishable from wild type (not shown). Broken lines denote basement membrane. Bar, $160 \mu \mathrm{m}$ in $A$ and $B ; 40 \mu \mathrm{m}$ in $\mathrm{C}$ and $\mathrm{D} ; 110 \mu \mathrm{m}$ in $\mathrm{E}$ and $\mathrm{G} ; 30 \mu \mathrm{m}$ in $\mathrm{F}$. 


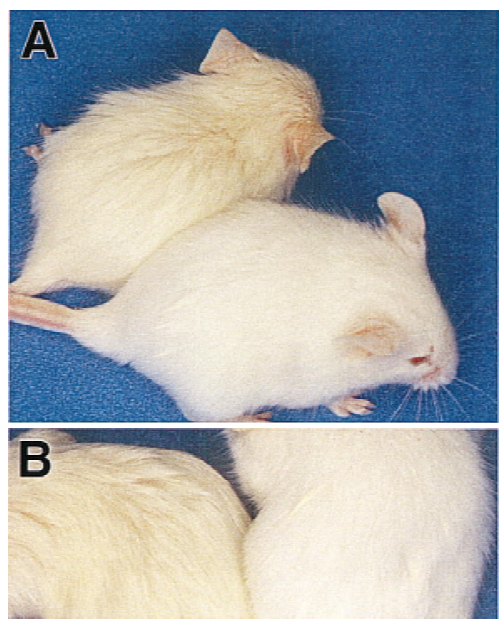

Figure 7. Aberrant hair coat of the $\mathrm{movol}^{-1-}$ mice. (A) movol $1^{-1-}$ mouse (top) and control littermate (bottom). (B) Close-up of the back area from mutant (left) and control (right) mice.

$6 \mathrm{E}-\mathrm{G})$. In all of these cases, the movol$^{-1-}$ skin was indistinguishable from wild type.

Whereas no obvious biochemical abnormalities were detected with the epidermal and hair-specific markers that we examined, the movol mice nevertheless began to devel op aberrations in their hair coat that were visible to the eye by the age of about two weeks (Fig. 7). By this time, movol ${ }^{-1-}$ mutant mice were distinguished from control littermates by their fuzzy, ruffled hair coat. This phenotype was somewhat more prominent in males, but was seen in both sexes. In addition, the movol ${ }^{-1-}$ mice were runted: On average, adult $(-t-)$ mice weighed 20\%-25\% less than littermates.

Scanning electron microscopy revealed structural abnormalities in the hairs of movol ${ }^{-1-}$ mice even at early ages (Fig. 8). A number of hairs displayed kinks and/or intercellular splits within or al ong the hair shafts. Such splits were predominantly seen in guard hairs, the longest and straightest of the four hair types (Dry 1926). Light microscopic examination of at least 50 plucked hairs from each type ( 1000 hai rs in total) confirmed that $16 \%$ of the guard hairs exhibited some signs of separation or splitting. Occasional auchene or awl hairs were also defective. In contrast, hairs plucked from control littermates showed no splits or alterations in any of the four hair types.

The abnormalities in the hai rs seemed to arise from a structural weakness or subtle change in the intercellular interactions within the hair shaft. However, at the ultrastructural level, we saw no obvious changes within the cells of the inner root sheath, outer root sheath, cuticle, cortex, or medulla (not shown). The restriction of aberrations to late-stage differentiation within the hair shaft is consistent with movol gene expression in the precortical cells of wild-type follicles. Precisely how movol expression might influence these intercellular interactions in the hair shaft awaits the identification and characterization of the genes regulated by movol.
Defects in the kidney and urogenital system of movol $^{-1-}$ mice

In situ hybridization revealed that movol RNAs in the wild-type kidney localize to the renal tubules of cortex and not to the glomeruli (Fig. 9, A, anti sense; B, sense). In movol ${ }^{t-}$ kidneys, defects were detected as early as 6 days postnatally; small cysts appeared within the developing cortex (Fig. 9C). The number and size of these epithelial cysts increased with age (Fig. 9E). In addition to these histological anomalies in the kidney, focal cystic dilation was sometimes observed in adult kidneys with accompanying signs of atrophy of surrounding renal tubules and glomeruli (not shown). Given their late onset, these changes are likely to be secondary consequences either from cyst formation within the kidney and/or from a defective urogenital system (see below).

U rogenital defects were particularly striking in female movol $1^{-1-}$ mice. Approximately $60 \%$ of adult female movol ${ }^{-1-}$ mice exhibited visibly moist skin in the external area surrounding the urogenital tract. This became so severe that in some cases, hair loss occurred in this region. When dissected and examined, these female mutants consistently showed a markedly dilated uterus and cervix, with some degeneration of the epithel ial lining of the lumen (not shown). In addition, the external vaginal opening was often constricted and in a few cases, completely fused (data not shown). At present, we do not yet know how mOvol might function to control such pro-
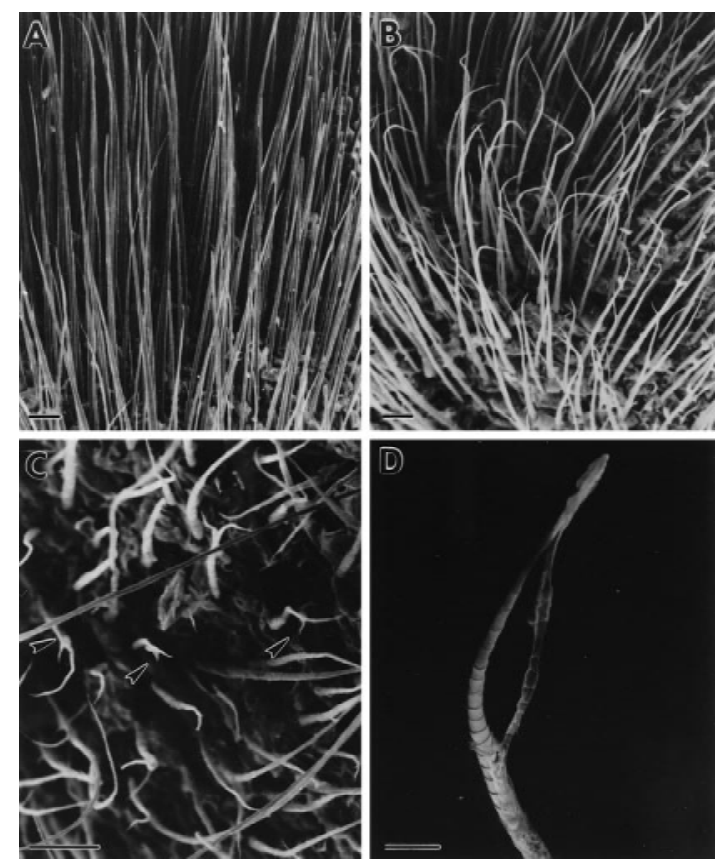

Figure 8. Scanning electron microscopy of skin surface from movol mutant and control mice. Back skins are from similar regions of an 8-day-old mutant mouse $(B, C)$ and control littermate (A). Arrowheads in $C$ denote splits at the hair ends. (D) Higher magnification of a mutant hair from the movol mouse to reveal intercellular nature of the split. Bar, $100 \mu \mathrm{m}$ in A-C; 10 $\mu \mathrm{m}$ in $\mathrm{D}$. 


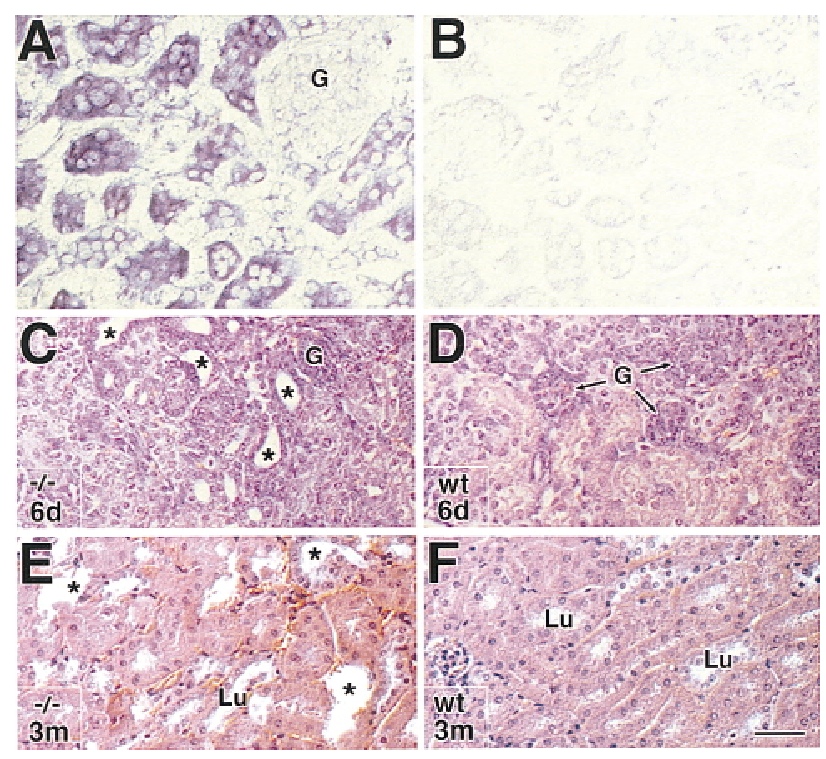

Figure 9. movol expression in kidney and effect of movol ablation on kidney morphology. $(A, B)$ In situ hybridizations of movol (A) or sense (B) probe on frozen sections of adult kidney. $\mathrm{N}$ ote hybridizing signals in kidney tubules but not in glomeruli $(G)$. (C,D) Kidneys from a 6-day-old mutant mouse (C) and littermate (D). (E,F) Kidneys from a 3-month-old mutant mouse (E) and littermate $(F)$. Asterisks $\left(^{*}\right)$ denote cysts in mutant kidneys not to be confused with tubule lumens (Lu). Bar, $75 \mu \mathrm{m}$.

cesses. This said, it is curious that whereas hair defects were more prominent in males, urogenital defects occurred predominantly in females. The possible relation between these sex-related al terations in mouse and the sex-related functions of ovo in flies awaits further investigation.

Cases of imperforate vagi na can occur at a frequency of up to $10 \%$ in some laboratory mouse strains (Sundberg and Brown 1994). However, none of the control littermates in our study displayed urogenital defects under conditions in which $60 \%$ of femal e movol mutant mice did so. These data argue that the observed structural malformations resulted from genetic manipulation of the movol locus. These al terations affected the mating ability of females; however, even when these mice were stimulated with hormone, superovulation resulted in normal numbers of eggs (data not shown).

\section{movol-related defects in late stage spermatogenesis}

In situ hybridizations of wild-type mature testis detected movol RNAs in primary and secondary spermatocytes, but not in spermatogonia (Fig. 10). These findings were interesting in that (1) Drosophila ovo/svb transcripts occur early, and not late, in male germ-cell development (Oliver et al. 1994; Mevel-Ninio et al. 1995); and (2) movo2 transcripts are expressed in testis only 3 weeks postnatally, that is, at a time when spermatogonia have given rise to spermatocytes ( $M$ asu et al. 1998). Taken together, these findings suggest an evolutionary differ- ence in transcriptional regulation of the ovo/svb class of genes in the mal e germ line, and a role for movo expression in late-stage differentiation of male germ cells.

Morphological defects in movol mutant testes correlated with the timing of movol expression in wild-type mice. During the first few weeks postnatal ly, testes appeared normal in size and morphology (Fig. 11, A and B, mutant vs. wild type). In contrast, by 4 weeks, testes were abnormally small: After correction for the overall reduction in body weight of the movol ${ }^{-1-}$ male mice, mutant testes were only $15 \%-50 \%$ the weight of normal testes (see Fig. 11C for intermediate example).

Two types of testis-related morphological defects were detected. In the 1-month-old mutant testis, the diameters of seminiferous tubules and the numbers of cells within tubules were atypically small (Fig. 11, D and E, respectively). Because testis size was not affected in younger animals, we surmise that this reduction is a reflection of a failure of germ-cell maturation and/ or survival. Consistent with this notion was a marked reduction in the number of mature spermatids that reached the lumen. Interestingly, a lack of vascularization was seen in the mutant testes (Fig. 11C), as was al so the case for mutant kidneys (not shown).

Additionally, seminiferous tubules of older mutant mice showed signs of degeneration (Fig. $11 \mathrm{~F}, \mathrm{H}, \mathrm{J}, \mathrm{K})$. Differentiating cells from the primary spermatocyte stage onward appeared defective. In severely affected testes, only a few spermatogonia survived (see Fig. 11K, arrowheads), and often Sertoli cells were the only remnants of the tubules $($ Fig. $11 \mathrm{H})$. Because defects in germ-cell survival were not detected early in postnatal testis devel opment, we surmise that they developed over time, perhaps as a secondary consequence of defective sperm production.

Despite defects in many seminiferous tubules, some produced sperm (Fig. 11],K). Moreover, whereas sperm production was greatly diminished, male movol mutant mice were not completely sterile.

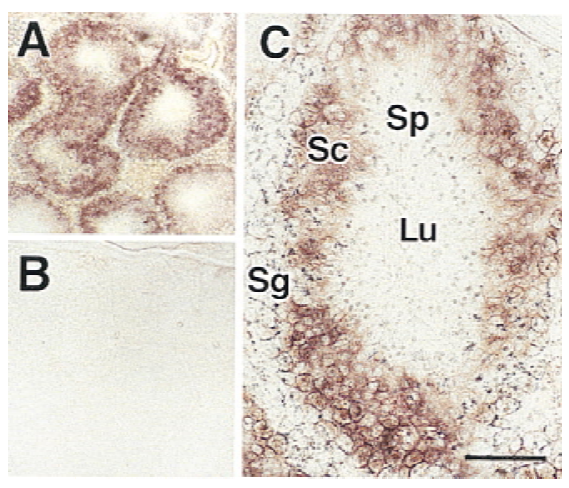

Figure 10. movol RN A expression in testis. In situ hybridizations of movol ( $A$ and $C$ ) or sense (B) probes on frozen sections of adult testis. $\mathrm{N}$ ote hybridization in germ cells of seminiferous tubules. Hybridization was not detected in spermatogonia (Sg), but was prominent in spermatocytes (Sc). (Lu) Lumen; (Sp) spermatids. Bar, $60 \mu \mathrm{m}$ in $\mathrm{C} ; 200 \mu \mathrm{m}$ in $\mathrm{A}$ and $\mathrm{B}$. 

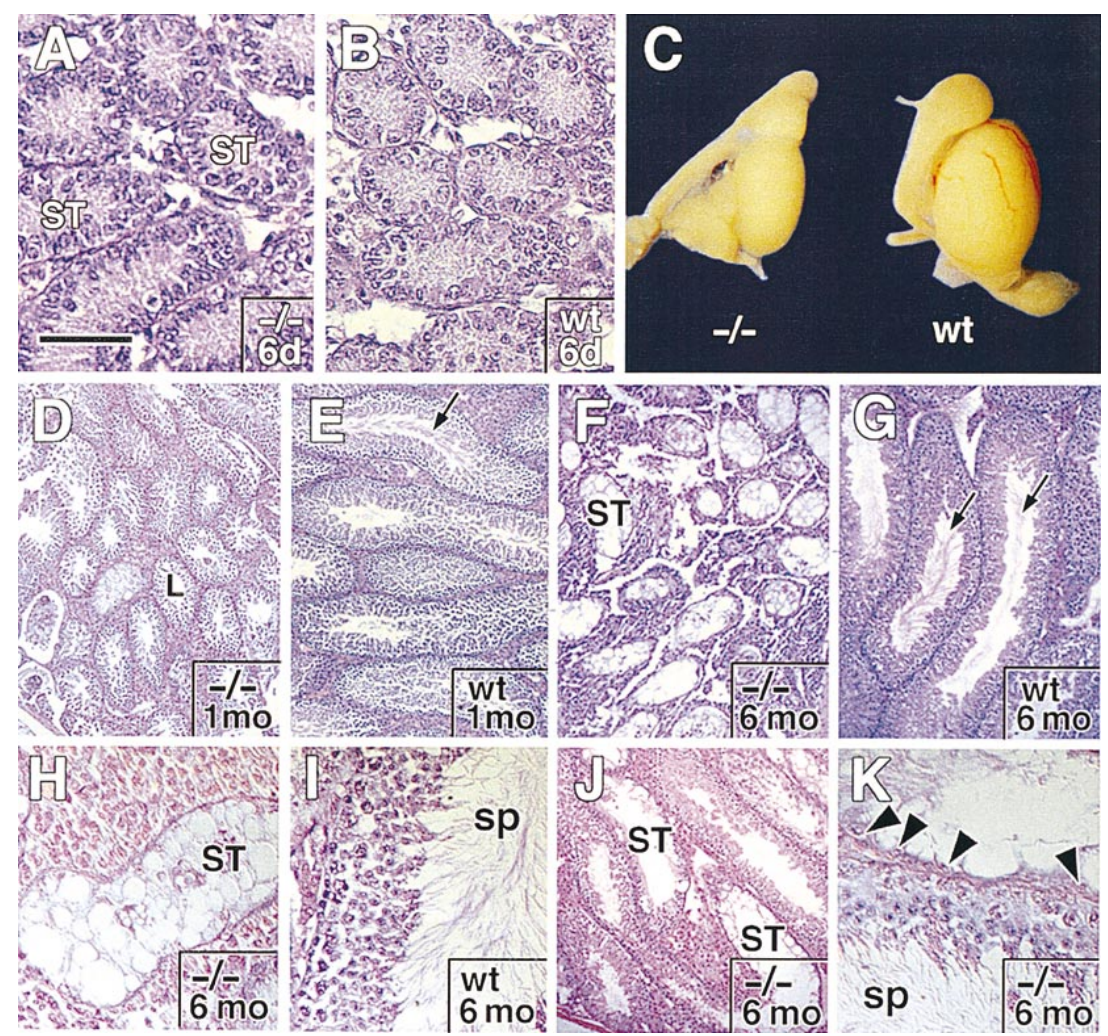

Figure 11. Morphological abnormalities in the movol mutant testes. Shown are hematoxylin- and eosin-stained sections of representative testes from movol $^{-1-}$ mice and control littermates (wt) at ages indicated. Whole testes are from 1-monthold mice; corresponding sections of these tissues reveal a dramatic difference in the size of the developing seminiferous tubules ( $D$ and $E$ are at same magnification). $\mathrm{N}$ ote the presence of sperm (arrows, SP) in lumen of mature wild-type, but not in most mutant, seminiferous tubules (ST). (K) Section of testis from mutant mouse that fathered five litters. The upper tubule was typical of $\mathrm{movol}^{-1-}$ testes: Arrowheads denote a few spermatogonia left in an otherwise degenerated seminiferous tubule; often only Sertoli cells remained. movol ${ }^{-1-}$ tubule in lower part of frame $\mathrm{K}$ displayed normal-looking sperm. Bar, $55 \mu \mathrm{m}$ in A and B; $6.5 \mathrm{~mm}$ in C; $280 \mu \mathrm{m}$ in D and $\mathrm{E} ; 240 \mu \mathrm{m}$ in $\mathrm{F}, \mathrm{G}$, and J; $60 \mu \mathrm{m}$ in $\mathrm{K}$.

\section{Discussion}

Similarities between fly and mouse epidermis

Fly larval epidermis is composed of a single layer of cells that secret a proteinaceous, extracellular cuticle (Fig. 12A). It also makes appendages such as ventral denticles and dorsal hairs, presumably providing sensory and locomotor functions. Cuticular appendage morphogenesis entails the transient formation of filopodia-like protrusions supported by the epidermal cell's cytoskel eton; following cuticl e secretion and hardening, these extensions retract, leaving a hardened, appendage-like structure at the fly's body surface (Martinez Arias 1993; Dickinson and Thatcher 1997).

In contrast, higher vertebrates display a stratified epidermis whose layers differ in proliferative capacity and differentiation status (Fig. 12B). Within the innermost, basal epi dermal layer, a small stem cell population gives rise to transi ently dividing cells with a limited proliferative capacity. Periodically, one of these cells withdraws from the cell cycle and commits to terminal differentiation. As the cell moves outward, it changes its program of gene expression to tailor a tough, resilient cytoskeleton. In this way, the protective material shed from the skin surface is cellular rather than secreted (Fuchs 1995). The major mammalian epidermal appendage is the hai $r$ follicle, which again is cellular, rather than extracellular (Hardy 1992).

As distinct as epi dermal morphogenesis may appear in these evol utionarily distant animals, some parallels still remain. Whether in fly or mouse, the epidermis must provide a protective armor to keep microorganisms out and essential bodily fluids in. In both species, the epidermis manifests this function by producing a single-layered epithelium that can execute a differentiative process. Whether secretory or cellular, surface appendages in both species are produced by epidermis late in embryogenesis (Hardy 1992; Martinez Arias 1993; Fuchs 1995). Even though the major structural genes of fly (cuticle) and mice (keratin) are not related, several of the genetic pathways that govern the patterning of appendages may be conserved (Parr and M cM ahon 1995; Willert and N usse 1997), a notion underscored by the recent discovery that mutations in the human patched gene, first identified as a fly epidermal gene, are responsible for basal-cell carcinomas (Hahn et al. 1996; Johnson et al. 1996).

Our studies on movol coupled with prior studies on ovo/svb (Oliver et al . 1987; M evel-N inio et al . 1991) now suggest that genetic parall els between fly and mouse epidermis go beyond the patterning of their appendages to the genes that are involved in structural aspects of epidermal differentiation and/or appendage formation. Thus, the ovo/svb class of genes encodes proteins with four evolutionarily conserved $\mathrm{Cys}_{2}-\mathrm{His}_{2}$ zinc-finger motifs that are involved in regulating cuticle/denticle formation in flies and hair differentiation in mice, both processes that occur late in differentiation. When taken together with evidence that Ovo/Svb are nuclear DNAbinding proteins (M evel-N inio et al. 1994; Lu et al . 1998), we anticipate that there will be downstream target genes for movol-encoded proteins that are involved in termi- 
A
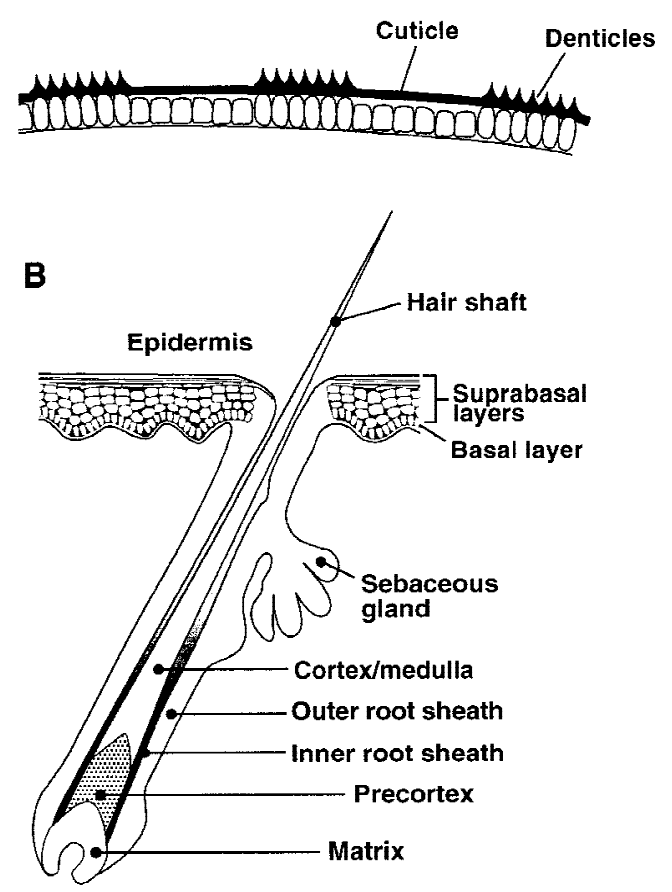

Figure 12. Schematic diagram of the fly and mouse epidermis. (A) Fly larval epidermis is composed of a single layer of cells. These cells are arranged in a specific spatial pattern such that those that make denticles al ternate with those that do not. Denticle formation occurs late in larval development, and stems from epithelial protrusions, hardened by cuticle secretion. (B) M ouse epidermis and hair follicles arise from a singlelayered embryonic ectoderm. In the adult, the epidermis is composed of a single layer of mitotically active basal cells and multiple layers of terminally differentiating suprabasal cells. The hair follicle is more complex. The cellular hair shaft arises from upward differentiation of matrix cells into precortex cells and finally into the cortex and medulla. It is encased by two cellular root sheaths, the outermost of which is contiguous with the epidermis.

nal differentiation in hair, and possibly in epidermis, in which movol is also expressed.

\section{mOvo and spermatogenesis}

In Drosophila, ovo is expressed in all germ cells, but its only function appears to be in female germ cells, where it is required for femal e sex determination and oogenesis (Comer et al. 1992; Oliver et al. 1994; M evel-N inio et al. 1995). In contrast, movo genes seem to have evolved to play a role in mammalian spermatogenesis. This is perhaps not surprising given that in mammals, the default pathway for germ-line sex determination has changed from mal e to female, and sex determination has evolved to differ quite dramatically from Drosophila (for review, see Pauli and M ahowald 1990; M cLaren 1995). In mice, movol does not appear to be required for sex determination, because at least some viable male and female homozygous mutant movol germ cells develop, resulting in a few successful matings of homozygous $\mathrm{movol}^{-1-}$ mice within the population.

The defects in movol mutant testes occurred late, concomitant with the late onset of movol expression in the testis. Interestingly, despite the lack of appreciable movol expression in spermatogonia, male germ-line stem-cell survival was al so affected, a process that coincided with major signs of tubule degeneration in adult animals. At present, we surmise that the defects in sperm production are primary, whereas those in male germ-cell survival and in testis vascularization are secondary. Regardless of the sequence of events, the degeneration seen in the mutant testes was among the most striking of the defects caused by movol mutation.

Abnormalities in the kidneys and urogenital tract of movol mutant mice

Given the phenotype of ovo/svb mutant flies, we had not anticipated defects in the kidney and urogenital tract of our movol mutant mice. However, it is interesting and likely relevant that the ovary, testis, and kidney share a common embryonic origin. These organs are derived predominantly from intermediate mesoderm, which undergoes extensive epithelial transformation to generate the ducts and tubules that compose urogenital tracts and kidneys (for review, see Saxen 1987). The tubule degeneration seen in the kidneys of our mice was similar to that seen in the testes. Our findings suggest that ovo/svb class of genes function in the differentiation and/or maintenance of the urogenital system.

A number of other transcription factors have been shown to govern the devel opment of the urogenital system (Pelletier et al. 1991; Satokata et al. 1995; Torres et al. 1995; M iyamoto et al . 1997). In particular, Pax2 seems to be essential in the early development of these structures, as Pax2 mutant mice lack kidneys, ureters, and genital tracts (T orres et al. 1995). In contrast, movol mutant mice seem to develop all of these structures normally but exhibit late-stage defects in the differentiation and/or maintenance of the kidneys and testes. As in the Pax2 mutant mouse, related endoderm-derived components, such as the bladder, urethra, and prostatic glands appear to be unaffected in movol mutant mice.

The existence of at least two ovo/svb genes in mice: functional redundancy or differential functions?

Given the existence of multiple movo genes (M asu et al. 1998), ovo/svb function may be even more important than what our movol mutant mice suggest. If the products of the different mouse ovo/svb-like genes share similar functions, then a threshold level of the encoded protein could be necessary to properly manifest normal differentiative functions in the organs where these genes are expressed. Alternatively, it could be that functions stemming from the ovo/svb locus in flies have evolved and diverged through gene duplication. In this fashion, we might expect that movo2 and other as yet unidenti- 
fied mouse ovo genes may encode Ovo/Svb-like proteins with distinct functions. Distinguishing between these possibilities must await future ablation of other movo genes and characterization of the multiple movo transcripts and their proteins.

\section{Do ovo genes play a role in human disease?}

The fact that movol mutant mice survive to adulthood and are not completely infertile raises the possibility that mutations in the equival ent human gene might give rise to a complex disorder involving hypogonadism, renal and urogenital defects, and mild hair abnormalities. Using FISH technology, we mapped the mouse ovol gene to a regi on of chromosome 19 cl ose to the centromere (J. Fantes, C. Schonbaum, and X. Dai, unpubl.). The equivalent region in the human genome is chromosome 11q13, where the human ovol gene was recently shown to reside (Chidambaram et al. 1997). Intriguingly, chromosomal rearrangements involving 11 q13 have been observed in extragonadal germ-cell tumors (Sinke et al. 1994) and in renal oncocytomas (van den Berg 1995). In addition, the genetic disorder Bardet-Biedl syndrome maps to this locus (Leppert et al . 1994; Beal es et al . 1997). This syndrome encompasses certain traits, such as mental retardation, post-axial polydactylia, obesity, and pigmentary retinopathy, that are inconsistent with those of the movol mutant mice. However, some Bardet-Biedl syndrome patients exhibit hypogenitalism in males, vaginal anomalies in females, and kidney/urogenital abnormalities (Leppert et al. 1994; C armi et al . 1995; O'Dea et al. 1996; Beal es et al . 1997). These traits are strikingly consistent with the defects seen in our movol mutant mice. Whereas the pleiotropic phenotypes associated with this syndrome seem to extend beyond those that can be accounted for by ovol, the complex nature of the ovo genes and the partial overlap in phenotypic traits between our mice and Bardet-Bi edl syndrome leave open the possibility that the ovol gene may be involved in this or perhaps other syndromes invol ving abnormal ities of the urogenital system.

\section{Materials and methods}

\section{Northern analysis}

Total skin RN As were isolated from frozen and powdered skin using the TRIzol reagent from GIBCO-BRL (Gaithersburg, MD). Poly(A) ${ }^{+}$-RN As were isolated using Oligotex (Qiagen, Val encia, CA ).Ovary poly $(A)^{+}-$RN As were purchased from Ambion (Austin, TX). N orthern blots containing other adult mouse tissues were purchased from Clontech (Palo Alto, CA). One of the following probes was used: a 1.0-kb fragment containing the $5^{\prime}$-end sequences of the movol cDN A including all four zinc fingers; a 350-bp fragment containing mostly $5^{\prime}$ UTR of movol; or a 1.2kb fragment containg the $3^{\prime}$ UTR and part of the coding sequences including three of the four zinc fingers. All three probes gave rise to similar results. Hybridizations were performed in ExpressHyb hybridization solution from Clontech at $68^{\circ} \mathrm{C}$, followed by two washes in $2 \times$ SSC, $0.05 \%$ SDS at room temperature, and three washes with $0.1 \times \mathrm{SSC}, 0.1 \% \mathrm{SDS}$ at $65^{\circ} \mathrm{C}$.

\section{In situ hybridization and immunofluorescence}

In situ hybridizations with digoxygenin-labeled CRNA probes were performed on frozen sections using the method of Schaeren-Wiemers and Gerfin-M oser (1993) with slight modifications: $10 \%$ heat-inactivated goat serum was used as the blocking agent prior to incubation with anti-digoxygenin antibody. Two different probes were used and yielded similar results: a 1.0-kb cRN A containing the four zinc fingers and upstream sequences; a 870-b cRNA containing the 3' UTR of movol.

Immunofluorescence microscopy was performed as described (Allen et al. 1996). A rabbit polyclonal antibody was generated by Zymed Laboratories (San Francisco, CA) to the peptide sequence CTSESQEGHVLHLKERHPDS at amino acid position 220 of mOvola protein. Antiserum was affinity purified on a peptide-conjugated column using the Sulfolink kit (Pierce, Rockford, IL) according to manufacturer's suggestions. Rabbit anti-Ioricrin was raised in the laboratory (E. Fuchs, K. Turksen, and $\mathrm{L}$. Milstone, unpubl.). AE13 was kindly provided by T.-T. Sun (N ew York University School of Medicine, NY).

\section{Transglutaminase assay}

Transglutaminase activity was measured using the following procedure. Frozen skin sections were fixed in methanol $\left(-20^{\circ} \mathrm{C}\right)$ for $20 \mathrm{~min}$, followed by $2 \times 5$-min washes in PBS. Sections were then incubated with a solution containing $2.5 \mathrm{~mm}$ DTT, $0.25 \%$ Triton X100, $0.15 \mathrm{M} \mathrm{N} \mathrm{aCl}, 0.05 \mathrm{M}$ Tris- $\mathrm{HCl}$ at $\mathrm{pH} 8.0,10 \mathrm{~mm}$ $\mathrm{CaCl}_{2}$, and $20 \%$ dansyl cadaverine, washed $3 \times 5$ min in PBS, and mounted as described (Allen et al. 1996). Transglutaminase activity was then detected by fluorescence microscopy.

\section{Cell culture and transient transfections}

M ouse keratinocyte line UG 1 (spontaneously immortal ized and cloned by Uri Gat in the laboratory) were cultured in media containing $\varangle 0.05 \mathrm{mM} \mathrm{Ca}^{2+}$ (Hennings et al. 1980). In Ca ${ }^{2+}$ induction experiments, $\mathrm{CaCl}_{2}$ was added to the subconfluent culture at a final concentration of $1.2 \mathrm{~mm}$, and cells were then maintained in high $\mathrm{Ca}^{2+}$ for desired period of time before harvesting. Full-length $2.0-\mathrm{kb}$ movola cDNA was released from the Bluescript vector by EcoRI-Aspl restriction and cloned into the Kpnl site of the mammalian expression vector pCB6(+) containing a CMV promoter and enhancer. Cos cells were transfected with the resulting plasmid using the cal cium-phosphate method (Wigler et al. 1978).

\section{Generation of movol $^{-1-}$ mice}

Full-length movol cDN A was used to screen a 129/Sv genomic library. One resulting cl one was subjected to detailed restriction map analysis and used to construct the targeting vector. The targeting vector was el ectroporated into R1 ES cells (passage 12) at $270 \mathrm{~V}, 500 \mu \mathrm{F}$ in a GenePulser (Bio-Rad Laboratories, Hercules, CA). ES cell culture and drug selection was essentially as described (Lo et al . 1997). ES clones positive for desired homologous recombination were injected into C57BL/ 6 blastocyst, and the resulting chimeric mice were crossed with C57BL/6. Germline transmission was obtained with two ES clones. Southern blot or PCR analysis was used for genotyping the ES clones and the mutant mice. For Southern bl ot analysis, genomic DN A was digested with Xbal-Xhol, HindlII, or Pvull, run on a $0.7 \%$ agarose gel, transferred to positively charged nylon membrane, and hybridized with either a $5^{\prime}$ (1.0-kb Xbal-EcoRI fragment) or a $3^{\prime}$ (1.5-kb Pstl-Xbal fragment) probe. 


\section{Histology}

Tissues were fixed in Bouin's fixative or in $4 \%$ formaldehyde, processed, and embedded in paraffin. Sections $(5 \mu \mathrm{m})$ were stained with hematoxylin and eosin, examined, and photographed using an Axiophot microscope (Carl Zeiss, Thornwood, NY).

\section{Electron microscopy}

Electron microscopic (EM) studies were kindly assisted by Edward Williamson at the Cancer Research Center EM facility of the U niversity of Chicago, IIlinois. For scanning EM, back skins of 8-day-old mutant mice and littermates were control fixed, processed, and examined as described (Guo et al. 1996).

\section{Acknowledgments}

We thank Janet Rossant and Andras Nagy at Mount Sinai Hospital, Toronto, for kindly providing us with R1 strain ES cells. Wethank Su Hao Lo and Liz Allen for their hel $p$ and advice with the mouse work. We are grateful to Ed Williamson for his expert hel $p$ at the EM facility, to Christoph Bauer and M ei Y in for their help in printing the EM pictures, and Chuck Wellek for his help in assembling the computer images for the figures. This work was supported by a grant from the $\mathrm{N}$ ational Institutes of $\mathrm{Heal}$ th (NIH) (AR31737). X.D. is the recipient of a postdoctoral fellowship from N IH (5 F32 AR08456-03). E.F. is an Investigator of the Howard Hughes Medical Institute.

The publication costs of this article were defrayed in part by payment of page charges. This article must therefore be hereby marked 'advertisement' in accordance with 18 USC section 1734 solely to indicate this fact.

\section{References}

Allen, E., Q.-C. Yu, and E. Fuchs. 1996. Abnormalities in desmosomes, proliferation and differentiation in the epidermis of mice expressing a mutant desmosomal cadherin. J. Cell Biol. 133: 1367-1382.

Andrews, J., I. Levenson, and B. Oliver. 1998. N ew AUG initiation codons in a long $5^{\prime}$ UTR create four dominant negative alleles of the Drosophila $\mathrm{C} 2 \mathrm{H} 2$ zinc-finger gene ovo. Dev. Genes Evol. 207: 482-487.

Beales, P.L., A.M. Warner, G.A. Hitman, R. Thakker, and F.A. Flinter. 1997. Bardet-Biedl syndrome: A molecular and phenotypic study of 18 families. J. Med. Genet. 34: 92-98.

Bogan, J.S. and D.C. Page. 1994. Ovary? Testis?-A mammalian dilemma. Cell 76: 603-607.

Busson, D., M. Gans, K. Komitopoulou, and M. M asson. 1983. Genetic analysis of three dominant female sterile mutations located on the X-chromosome of Drosophila melanogaster. Genetics 105: 309-325.

Byrne, C., M. Tainsky, and E. Fuchs. 1994. Programming gene expression in developing epidermis. Development 120: 23692383.

Capel, B. 1998. Sex in the 90s: SRY and the switch to the male pathway. Annu. Rev. Physiol. 60: 497-523.

Carmi, R., K. Elbedour, E.M. Stone, and V.C. Sheffield. 1995. Phenotypic differences among patients with Bardet-Biedl syndrome linked to three different chromosome loci. Am. J. Med. Genet. 59: 199-203.

Chidambaram, A., R. Allikmets, S. Chandrasekarappa, S.C. Guru, W. Modi, B. Gerrard, and M. Dean. 1997. Character- ization of a human homolog (OVOL1) of the Drosophila ovo gene, which maps to chromosome 11q13. Mamm. Genome 8: 950-951.

Cline, T.W. and B.J. Meyer. 1996. Vive la difference: Males vs. females in flies vs. worms. Annu. Rev. Genet. 30: 637-702.

Comer, A.R., L.L. Searles, and L.J. Kal fayan. 1992. Identification of a genomic DN A fragment containing the Drosophila melanogaster ovarian tumor gene (otu) and localization of regions governing its expression. Gene 118: 171-179.

Dickinson, W.J. and J.W. Thatcher. 1997. M orphogenesis of denticles and hairs in Drosophila embryos: Involvement of actin-associated proteins that al so affect adult structures. Cell Motil. Cytoskel. 38: 9-21.

Dry, F.W. 1926. The coat of the mouse (Mus musculus). J. Genet. 16: 287-340.

Fuchs, E. 1995. Keratins and the skin [Review]. Annu. Rev. Cell Devel. Biol. 11: 123-153.

Garfinkel, M.D., A.R. Lohe, and A.P. M ahowald. 1992. M olecular genetics of the Drosophila melanogaster ovo locus, a gene required for sex determination of germline cells. Genetics 130: 791-803.

Garfinkel, M.D., J. Wang, Y. Liang, and A.P. Mahowald. 1994. Multiple products from the shavenbaby-ovo region of Drosophila melanogaster: Relationship to genetic complexity. Mol. Cell Biol. 14: 6809-6818.

Granadino, B., P. Santamaria, and L. Sanchez. 1993. Sex determination in the germline of Drosophila melanogaster: Activation of the gene Sex-lethal. Development 118: 813-816.

Guo, L., L. Degenstein, and E. Fuchs. 1996. Ablation of keratinocyte growth factor in mice: Skin changes but no aberrancies in wound-healing. Genes \& Dev. 10: 165-175.

Hahn, H., C. Wicking, P.G. Zaphiropoulos, M.R. Gailani, S. Shanley, A. Chidambaram, I. Vorechovshky, E. Holmberg, A.B. Unden, S. Gillies et al. 1996. Mutations of the human homolog of Drosophila patched in the nevoid basal cell carcinoma syndrome. Cell 85: 841-851.

Hardy, M.H. 1992. The secret life of the hair follicle. Trends Genet. 8: 159-166.

Hennings, H., D. Michael, C. Cheng, P.M. Steinert, K. Holbrook, and S.H. Yuspa. 1980. Calcium regulation of growth and differentiation of mouse epidermal cells in culture. Cell 29: $245-254$.

Hillier, L., N. Clark, T. Dubuque, K. Elliston, M. Hawkins, M. Holman, M. Hultman, T. Kucaba, M. Le, G. Lennon et al. 1996. Washington University-Merck EST Project. mouseest@watson.wustl.edu.

Johnson, R.L., A.L. Rothman, J. Xie, L.V. Goodrich, J.W. Bare, J.M. Bonifas, A.G. Quinn, R.M. Myers, D.R. Cox, E.H. Epstein, Jr., and M .P. Scott. 1996. Human homolog of patched, a candidate gene for basal cell nevus syndrome. Science 272: 1668-1671.

Leppert, M., L. Baird, K.L. A nderson, B. Otterud, J.R. Lupski, and R.A. Lewis. 1994. Bardet-Biedl syndrome is linked to DNA markers on chromosome $11 \mathrm{q}$ and is genetically heterogeneous. Nat. Genet. 7: 108-112.

Lin, H. 1997. The tao of stem cells in the germline. Ann. Rev. Genet. 31: 455-491.

Lo, S.H., Q.C. Yu, L. Degenstein, L.B. Chen, and E. Fuchs. 1997. Progressive kidney degeneration in mice lacking tensin. J. Cell Biol. 136: 1349-1361.

Lu, J., J. Andrews, D. Pauli, and B. Oliver. 1998. Drosophila OVO zinc-finger protein regulates ovo and ovarian tumor target promoters. Dev. Genes Evol. 208: 213-222.

Martinez Arias, A. 1993. Development and patterning of the Iarval epidermis of Drosophila. In The development of Drosophila melanogaster (ed. M. Bate and A. Martinez Arias), 
pp. 517-608. Cold Spring Harbor Laboratory Press, Cold Spring Harbor, NY.

M asu, Y., S. Ikeda, E. Okuda-A shitaka, E. Sato, and S. Ito. 1998. Expression of murine novel zinc finger proteins highly homologous to Drosophila ovo gene product in testis. FEBS Lett. 421: 224-228.

McLaren, A. 1995. Germ cells and germ cell sex. Phil. Trans. Roy. Soc. London-Series B: Biol. Sci. 350: 229-233.

Mevel-N inio, M., R. Terracol , and F.C. Kafatos. 1991. The ovo gene of Drosophila encodes a zinc finger protein required for female germline devel opment. EMBO J. 10: 2259-2266.

Mevel-Ninio, M., R. Terracol, C. Salles, A. Vincent, and F. Payre. 1995. Ovo, a Drosophila gene required for ovarian development, is specifically expressed in the germline and shares most of its coding sequences with shavenbaby, a gene involved in embryo patterning. Mech. Dev. 49: 83-95.

Mevel-Ninio, M., E. Fouilloux, I. Guena, and A. Vincent. 1996. The three dominant female-sterile mutations of the Drosophila ovo gene are point mutations that create new transIation-initiator AUG codons. Development 122: 4131-4138.

Miyamoto, N., M. Yoshida, S. Kuratani, I. Matsuo, and S. Aizawa. 1997. Defects of urogenital development in mice lacking Emx2. Development 124: 1653-1664.

O'D ea, D., P.S. Parfrey, J.D. Harnett, D. Hefferton, B.C. Cramer, and J. Green. 1996. The importance of renal impairment in the natural history of Bardet-Biedl syndrome. Am. J. Kid. Dis. 27: 776-783.

Oliver, B., N. Perrimon, and A.P. Mahowald. 1987. The ovo locus is required for sex-specific germ line maintenance in Drosophila. Genes \& Dev. 1: 913-923.

Oliver, B., D. Pauli, and A.P. M ahowald. 1990. Genetic evidence that the ovo locus is involved in Drosophila germ line sex determination. Genetics 125: 535-550.

Oliver, B., J. Singer, V. Laget, G. Pennetta, and D. Pauli. 1994. Function of Drosophila ovo+ in germline sex determination depends on X-chromosome number. Development 120: 31853195.

Parr, B.A. and A.P. M cM ahon. 1995. Dorsalizing signal Wnt-7a required for normal polarity of $\mathrm{D}-\mathrm{V}$ and $\mathrm{A}-\mathrm{P}$ axes of mouse limb. Nature 374: 350-353.

Pauli, D. and A.P. Mahowald. 1990. Germline sex determination in Drosophila melanogaster. Trends Genet. 6: 259-264.

Pauli, D., B. Oliver, and A.P. Mahowald. 1993. The role of the ovarian tumor locus in Drosophila melanogaster germline sex determination. Development 119: 123-134.

Pelletier, J., W. Bruening, C.E. Kashtan, S.M. Mauer, J.C. Manivel, J.E. Striegel, D.C. Houghton, C. Junien, R. Habib, L. Fouser, R.N . Fine, B.L. Silverman, D.A. Haber, and D. Housman. 1991. Germline mutations in the Wilms' tumor suppressor gene are associated with abnormal urogenital development in Denys-Drash syndrome. Cell 67: 437-447.

Satokata, I., G. Benson, and R. M aas. 1995. Sexually dimorphic sterility phenotypes in Hoxal0-deficient mice. Nature 374: 460-463.

Saxen, L. 1987. Organogenesis of the kidney. Dev. Cell Biol. Ser. 19.

Schaeren-Wiemers, N . and A. Gerfin-M oser. 1993. A single protocol to detect transcript of various types and expression levels in neural tissue and cultured cells: In situ hybridization using digoxigenin-labelled cRN A probes. Histochemistry 100: 431-440.

Sinke, R.J., D.O. Weghuis, R.F. Suijkerbuijk, A. Tanigami, Y. N akamura, C. Larsson, G. Weber, B. de Jong, J.W. Oosterhuis, W.M. Molenarr et al. 1994. M olecular characterization of a recurring complex chromosomal translocation in two human extragonadal germ cell tumors. Cancer Genet. Cyto- genet. 73: 11-16.

Sundberg, J.P. and K.S. Brown. 1994. Imperforate vagina and mucometra in inbred laboratory mice. Lab. Anim. Sci. 44: 380-382.

Torres, M., E. Gomez-Pardo, G.R. Dressler, and P. Gruss. 1995. Pax-2 controls multiple steps of urogenital development. Development 121: 4057-4065.

Van den Berg, E., T. Dijkhuizen, S. Storkel, G. Brutel de la Riviere, A. Dam, H.J.A. Mensink, J.W. Oosterhuis, and B. de Jong. 1995. Chromosomal changes in renal oncocytomas. Canc. Genet. Cytogenet. 79: 164-168.

Wei, G. and A.P. M ahowald. 1994. The germline: Familiar and newly uncovered properties. Annu. Rev. Genet. 28: 309-324.

Wieschaus, E., C. N üsslein-Wol hard, and G. Jurgens. 1984. M utations affecting the pattern of the larval cuticle in Drosophila melanogaster. III. Zygotic loci on the X-chromosome and the fourth chromosome. Wilhelm Roux's Arch. Dev. Biol. 193: 296-307.

Wigler, M., A. Pellicer, S. Silverstein, and R. Axel. 1978. Biochemical transfer of single-copy eucaryotic genes using total cellular DNA as donor. Cell 14: 725-731.

Willert, K. and R. N usse. 1998. Beta-catenin: A key mediator of Wnt signaling. Curr. Opin. Genet. Dev. 8: 95-102. 


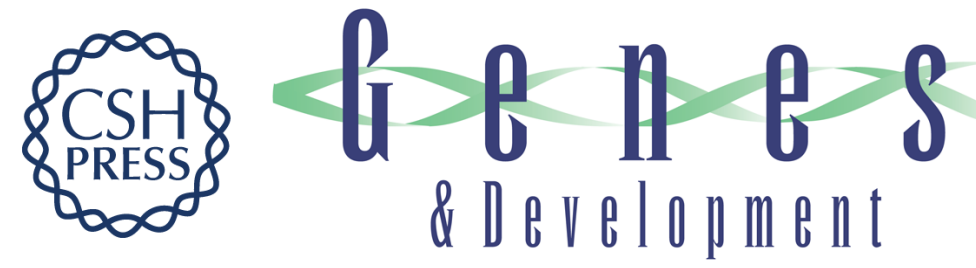

\section{The ovo gene required for cuticle formation and oogenesis in flies is involved in hair formation and spermatogenesis in mice}

Xing Dai, Christopher Schonbaum, Linda Degenstein, et al.

Genes Dev. 1998, 12:

Access the most recent version at doi:10.1101/gad.12.21.3452

References

This article cites 49 articles, 17 of which can be accessed free at: http://genesdev.cshlp.org/content/12/21/3452.full.html\#ref-list-1

License

Email Alerting

Receive free email alerts when new articles cite this article - sign up in the box at the top Service right corner of the article or click here.

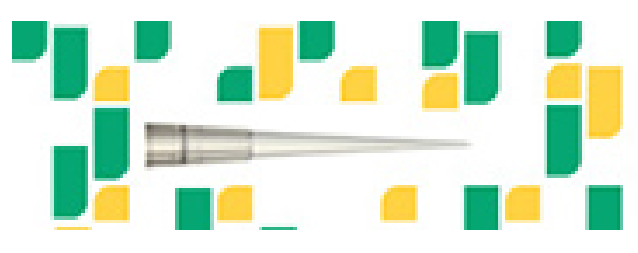

Focused on your science. 